\section{EREM 77/4}

Journal of Environmental Research, Engineering and Management

Vol. 77 / No. 4 / 2021

pp. 86-98

DOI 10.5755/j01.erem.77.4.25043
Prevention of Littering through Improved Visual Design

Received 2020/01

Accepted after revision 2021/11

\title{
Prevention of Littering through Improved Visual Design
}

\author{
Hendro Putra Johannes*, Rheza Maulana, Herdis Herdiansyah
}

School of Environmental Science, Universitas Indonesia, Central Jakarta, DKI Jakarta 10430, Indonesia

*Corresponding author: hendro.johannes21@gmail.com

Littering is a daunting environmental issue that occurs daily; the impact of littering can range from lowering the aesthetic appeal of a city to polluting waterways and biomes. Littering persists on a collective and individual level despite the existence of numerous laws and regulations that prohibit it. We assume that there is a correlation between the effectiveness of visual aids and littering behavior. Poorly designed prohibitive signs and inaccessible trash bins could be part of the reason why littering persists. The current research aims to evaluate existing prohibitive signs and trash bins and to design some improvements. The researchers used direct observation methods of visual designs based on socio-psychological persuasion techniques and a questionnaire conducted at the School of Environmental Science of Universitas Indonesia. The results showed that respondents were generally aware of littering being a serious issue that could lead to environmental problems. The university campus was generally clean; however, respondents stated that they often saw plastic trash in sewer and drainage areas. University residents do litter despite adverse social judgment. In addition, respondents stated that they responded better to visually pleasing encouragement posters rather than the standard prohibitive signs on proper waste disposal behavior.

Keywords: plastic littering, waste, visual design, socio-psychological persuasion. 


\section{Introduction}

Littering is a daunting issue faced by large cities. It is a worldwide behavioral problem that needs systematic review and solutions (Almosa et al., 2017). Previous studies have shown a reduction in littering after certain interventions were used. For example, Brown et al. (2010) found a 15\%-20\% increase in a litter pick up after their study intervention. Other studies have covered the following related issues: the "watching eyes" effect, where the visual representation of eyes is enough to encourage people to behave in a more honest and pro-social manner (Bateson et al., 2013); formative research to gain insights into the motives, opportunities, barriers, and triggers (Tapp and Rundle-Thiele, 2016); and a set of salient beliefs that could be used to influence park visitors (Brown et al., 2010).

Although these studies indicate that littering has reduced, other studies state that there is still no major change in littering behavior (Taylor et al., 2007). This is reflected by several facts regarding plastic waste. As much as 5 trillion plastic bags are consumed in the world annually (UNEP, 2018), and about 8 million of these are thrown into the ocean (EPI, 2014; Ocean Conservancy and McKinsey Center, 2017; Geyer et al., 2017; UNEP, 2018). This trash endangers sea creatures, including turtles, fish, seahorses, jellyfish, and whales (WEF, 2016; UNEP, 2018). Indonesia is the second largest producer of marine plastic waste (Jambeck et al., 2015). Moreover, the shocking news of a dead sperm whale with more than 13 pounds $(6 \mathrm{~kg})$ of plastic waste in its stomach washing up on a beach in Wakatobi has served to remind the people of Indonesia about the impact of littering (BBC News, 2018).

Littering - an act of disposing waste improperly - has led to immense environmental degradation. In Jakarta, the capital city of Indonesia, littering is at epidemic proportions even though there are existing laws that prohibit it (Barley, 2011). People of various backgrounds are reminded daily that littering is essentially a crime punishable by law. Why, then, does littering still exist?

Warnings and prohibitions have not been very effective at solving the problem, because human beings innately dislike being told what to do, even when there are penalties involved. Perhaps, it would be more effective to encourage people to stop littering by more positive means than by scaring them with penalties and punishments (Police Executive Research Forum, 2016). It is a known fact that signs and posters with different colors, shapes, and designs affect human psychology (Holland et al., 2015). For example, restaurants use red and yellow in their logos, because these colors are associated with food and subliminally increase appetite (Cerrato, 2012). The same approach could be implemented with interestingly designed signs that would encourage people to willingly dispose of their waste in trash bins rather than littering. Thus, a socio-psychological approach could offer an interesting and useful aspect to the current research. The present study aims to evaluate the existing prohibitive signage regarding littering and to offer a basis for designing improved alternatives. The study also analyzes these alternatives with the responses they evoke within the local community.

\section{Current Littering Issues}

According to Long et al. (2015), individuals' beliefs and behaviors regarding litter have improved following a littering and recycling intervention in a New Zealand high school community. Respected and well-known role models together with supportive peer norms have exerted a positive influence on littering behavior. These results are consistent with White and Hyde's (2011) research, which suggests that injunctive norms (what people feel is morally correct behavior) and descriptive norms (what people end up doing based on what others are doing around them) can be used together to encourage responsible waste management behaviors. These include social constructions such as peer pressure and building a conducive atmosphere to set up a particular targeted behavior (Brown et al., 2008; Brechwald and Prinstein, 2011).

Attitudes toward littering are a major issue in affecting environmental management. Ojedokun (2011) has shown that attitudes toward littering mediate the 
relationship of locus of control and altruism with responsible environmental behavior. This is illustrated in Fig. 1. The influence of the personality attributes may offer a bridge between self-concept and self-efficacy (Ojedokun and Balogun, 2010, 2011).

Fig. 1. Framework of attitudes toward littering as mediator of personality attributes and responsible environmental behavior (Source: Ojedokun, 2011)

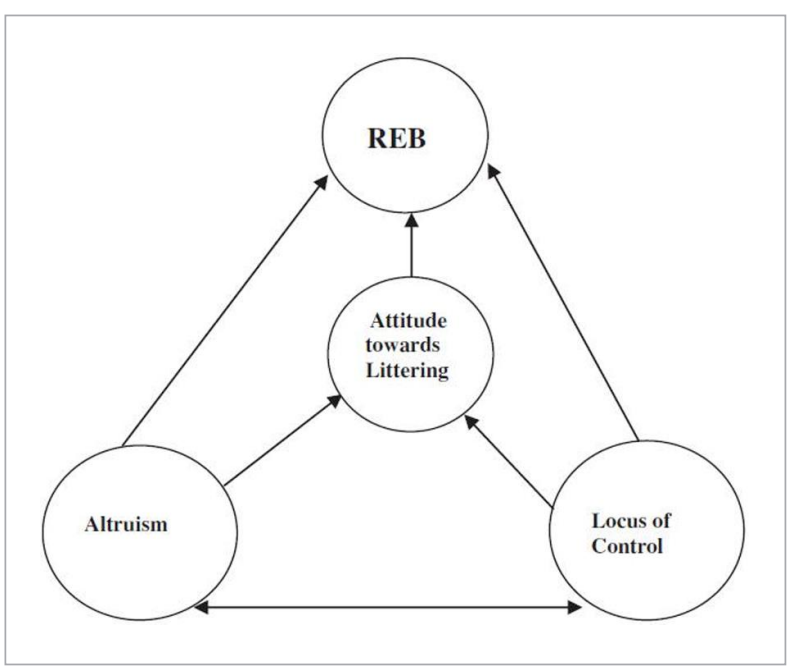

Bateson et al. (2013) researched how visual design influences people's behavior regarding the environment. The visual design in the study included images of eyes to underscore what has been referred to as the watching eyes effect, in which such images tend to encourage people to behave in a more pro-social manner. This effect was first studied in the gaming experiments of Burnham and Hare (2007). Other researchers have examined this phenomenon by comparing the behavior of subjects while transferring money in the presence of an image of eyes or a control image (Keller and Pfattheicher, 2011; Oda et al., 2011; Netthe et al., 2012). The watching eyes effects have also affected several conditions regarding public decisions: for example, paying via an honesty box (Bateson et al., 2006), donating to charity (Powell et al., 2012), recycling (Francey and Bergmüller, 2012), stealing bicycles from campuses (Nettle et al., 2012), and leaving litter on café tables (Ernest-Jones et al., 2011).

\section{Design-based Socio-psychological Persuasion}

Social aspects will be less meaningful and difficult to internalize without psychological aspects: for example, from the visual design. In the case of littering prevention, visual design appears to address the ineffectiveness of current infrastructure conditions related to littering behavior: for example, the waste bin design or persuasion not to litter. Some previous reviews or studies have been examined to resolve this issue.

There are a few rules that must be addressed to achieve visually pleasing design, and the first one is proportion. The Golden Ratio is used to create aesthetically pleasing visuals (Batista and Filho, 2019). It is a ratio based on mathematical calculations transformed into a visual image. One famous example is the "Mona Lisa," shown in Fig. 2.

Fig. 2. Golden Ratio of Mona Lisa (Source: Da Vinci, 1503; modified by Bo et al., 2018)

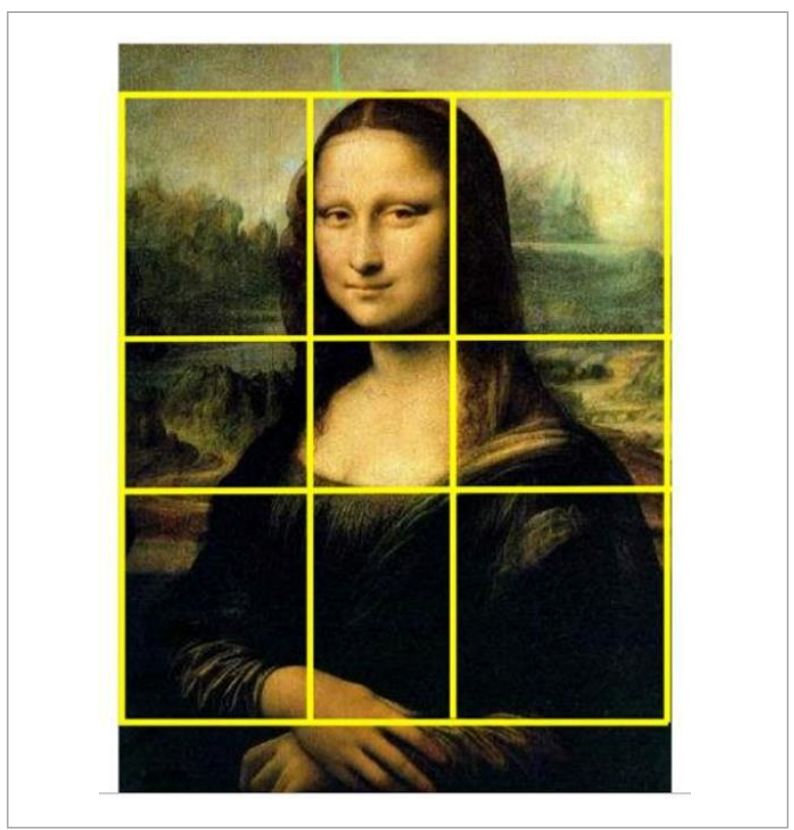

Another rule of proportion is the Rule of Thirds, which entails dividing an image into $3 \times 3$ equal grids, where the foreground object at an intersection point or on a 
dividing line would make the composition more interesting and aesthetic (Bo et al., 2018). The implementation of the Rule of Thirds is shown in Fig. 3.

Fig. 3. Application of the Rule of Thirds (Source: The Beat, 2017)

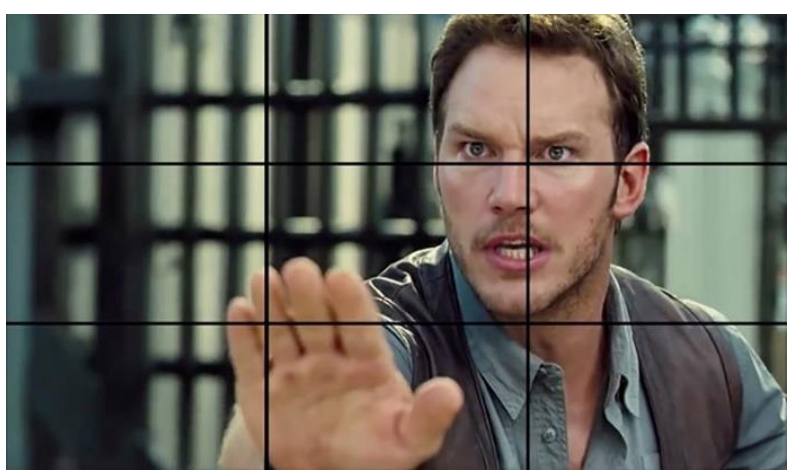

Elements of design such as shape, color, texture, and contrast are also important (Liu, 2018). For example, different colors have different effects on our psychological state, and these effects could be utilized for a designer's purposes. Examples include the use of the colors red and yellow by fast food companies, as these are the colors that stimulate appetite; see Fig. 4.

Fig. 4. Utilization of red and yellow in brands (Source: Thrive Advertising, 2012)

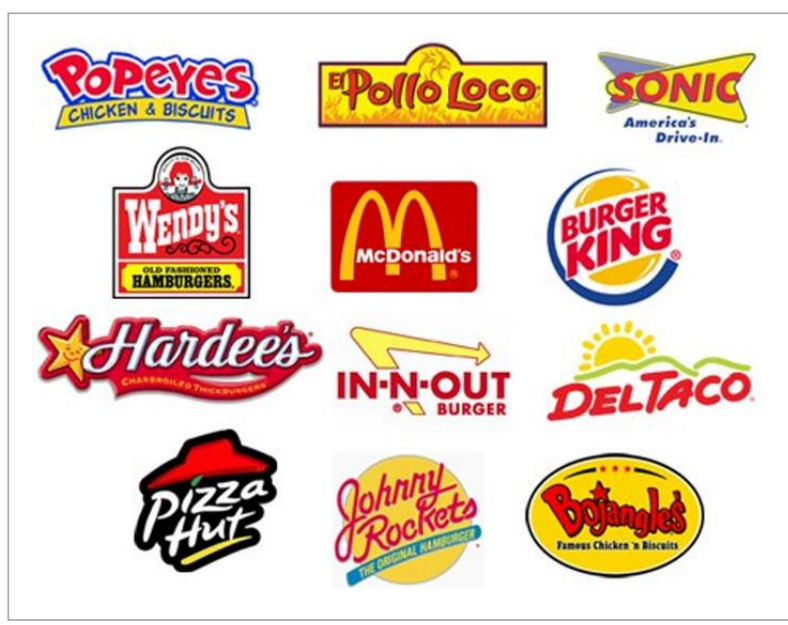

Some colors are meant to be vividly seen and to be eye-catching. Others are meant to be hidden. Invisible colors are often used for objects that are not meant to be seen by the public. These colors are generally grayish shades. One example is the Club 33 Lounge at Disneyland, an exclusive lounge that is not open to the public. The entrance to the lounge is painted a grayish green color, so that visitors often pass it without even noticing (Talltanic, 2018). As seen in Fig. 5, the lounge entrance's dull color is unnoticeable compared with the vivid red next to it.

Fig. 5. Application of invisible colors (Source: Mxreb0, 2006)

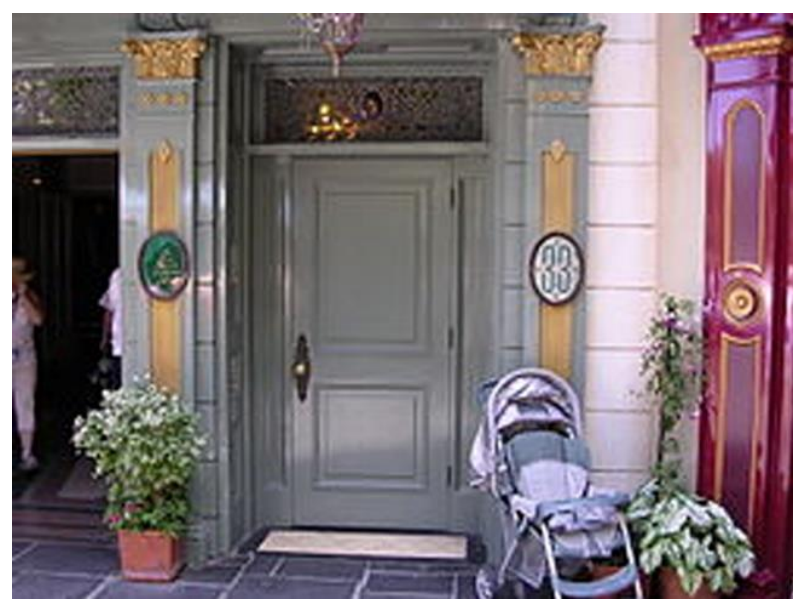

Color contrast is key to creating a visually pleasing and well-received visual aid. Fig. 6 gives a table showing appropriate foreground/background color combinations. Thus, for a red background, it would be better to use white letter fonts in the foreground (Fig. 7A) than black fonts (Fig. 7B). In this example, although both signs are generally well proportioned, Fig. 7A shows a vividly eye-catching image compared with Fig. 7B, in which the image appears darker and less noticeable.

Finally, visual hierarchy also needs to be taken into account (Eldesouky, 2013). Visual hierarchy is about arranging the elements of design in a presentation based on their level of importance. According to this approach, the more important the element, the more focused, clear, and close to the eye of the observer it should be. Conversely, the more insignificant the element, the more out of focus, less sharp and precise, and farther from the viewer it should be. Fig. 8 illustrates visual hierarchy principles. 
Fig. 6. Perception of combinations of foreground and background colors (Source: Thomas, 2018)

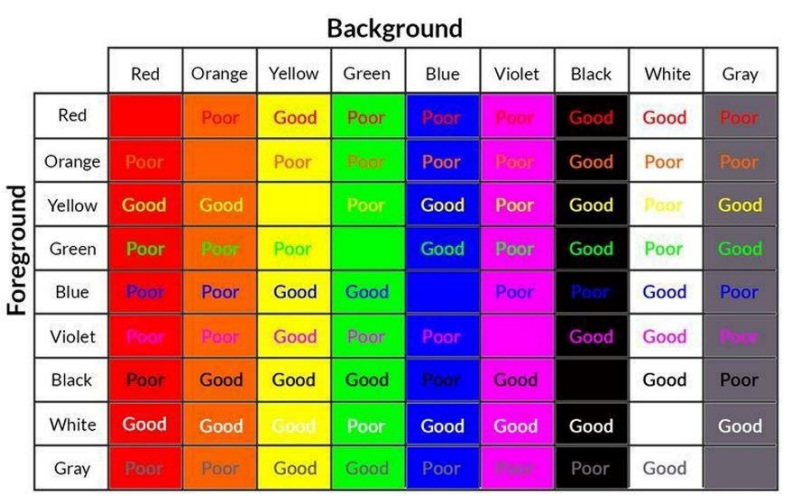

Fig. 7. (A) Balanced contrast; (B) imbalanced contrast (Source: Keep Calm and Posters, 2015)

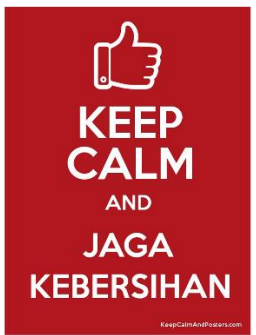

A

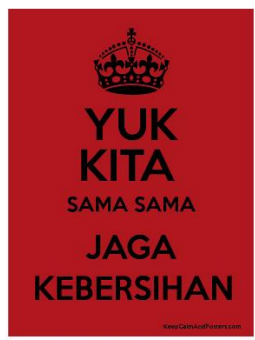

B
Fig. 8. Visual hierarchy in visual design (Source: Share Faith, 2013)

\section{READTHISFIRST}

\section{and then read this.}

\section{Methods}

\section{Design}

A total of four designs were specifically made for the purpose of this research. The first was "Warning signs" made based on design-based socio-psychological persuasion theories regarding images that were considered to be visually pleasing. The second was

"Trash bin labels" to encourage people to dispose their trash correctly through the aid of a more informative labels. The third - "Trash bin design" - included physically designing a trash bin product that is deemed to be more compact, accessible, and informative. The fourth was "Encouragement poster" as alternative means aside from warnings, but more of an indirect encouragement without hints of punishments from failing to commit it. We wanted to know if the public would rather have this kind of posters compared with warning posters, so this design would then be compared with a conventional warning sign.

\section{Participants}

This research is a case study in Jakarta, Indonesia, at the School of Environmental Science of Universitas Indonesia (SIL UI) in 2019. This school was chosen because some students there are taking a master's or doctoral degree in Environmental Science. These participants became agents of change in the fight to stop littering (Healey, 2015). Having obtained an increased awareness of environmental issues during the study, participants would hopefully help in the movement to prevent littering, even if only within the school grounds. Essentially, the opinions of the participants were intended to evaluate the effectiveness and efficiency of the interventions made by the authors regarding better visual designs. The opinions of the participants were gathered with their consent ethically, they were not forced to participate and their identities were anonymous to further keep their privacy. The considerations made were intended to follow the Declaration of Helsinki (2013), regarding human subjects.

\section{Instrument}

The research was conducted through means of direct observation, visual design based on socio-psychological persuasion (Burnham and Hare, 2007; Ojedokun and Balogun, 2010; Bateson et al., 2013; Eldesouky, 2013; Liu, 2018; Batista and Filho, 2019), and a simple questionnaire of multiple-choice questions.

\section{Procedure}

Direct observation was conducted through exploring a real litter condition and current visual aid designs, taking photographs, and explaining the condition. Based 
on the direct observation, we then created a new alternative visual design based on socio-psychological persuasion (Burnham and Hare, 2007; Ojedokun and Balogun, 2010; Bateson et al., 2013; Eldesouky, 2013; Liu, 2018; Batista and Filho, 2019). Afterwards, we analyzed community responses regarding the alternatives suggested through the simple questionnaire: multiple-choice questions asking about alternatives for improvements.

\section{Data Analysis}

There were two kinds of data to analyze. The first was current littering conditions and the second was public perception. The first data were gathered through direct observation, and we determined whether or not signs and trash bin were present in the area of the research. We also cross-checked the findings with the presence of litter, and other improperly placed waste in the surrounding area. We would then analyze the correlation between the presence of signs and trash bins, and the presence of litters. If the data showed that signs and trash bins were present, yet litters were still found in the area, we would then find the probable reasoning for such a condition. Once we found the probable reasoning, we then tried to find a corrective solution by implementing theories of design-based socio-psychological persuasion. The second data were gathered from the participants' answers from the questionnaire, whether or not they preferred conventional design or design-based socio-psychological persuasion alternatives. The participants' answer would indicate their preference, and should they have positive reception to the alternatives, it would mean that the design-based socio-psychological persuasion could affect people's behavior in the prevention littering.

\section{Results and Discussion}

As a quick image search will show, not enough forethought goes into creating and positioning the signage about littering and trash management, and therefore design errors (as seen in Fig. 7B) are common. The researchers conducted a field observation at SIL UI: they found that the signage about littering and trash management was relatively normative in design and often not visually appealing, and the trash bin tools were not placed strategically about the signs.

Generally, SIL UI in 2019 was relatively clean; however, litter could still be seen here and there, most often in places such as gutters and drains. As seen in Fig. 9, litter could be found even when there was a trash bin nearby. To be fair, the people who litter are not entirely to blame. The field observation also showed

Fig. 9. (A) Plastic litter near a trash bin; (B) plastic litter in a gutter

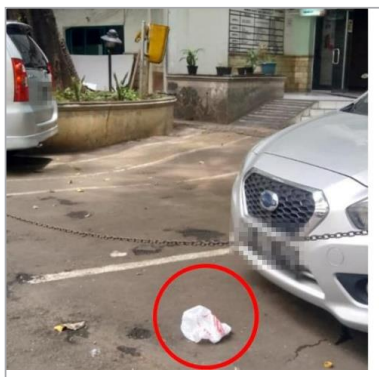

A

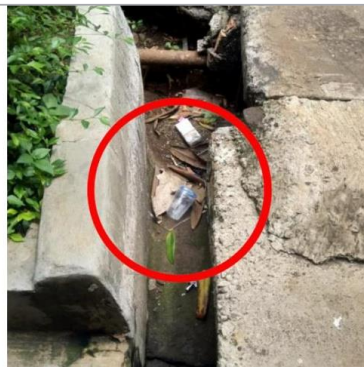

B
Fig. 10. Hidden trash bin

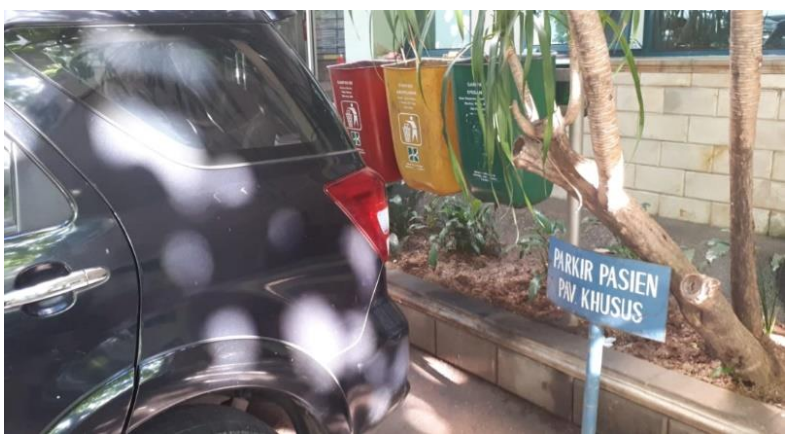

Fig. 11. (A) Existing problem; (B) unrealistic solution

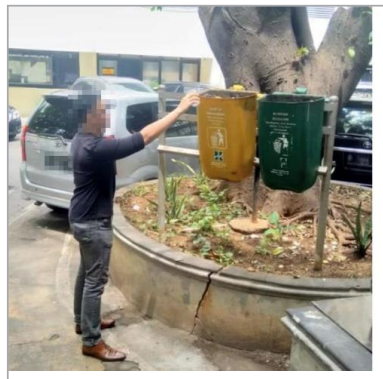

A

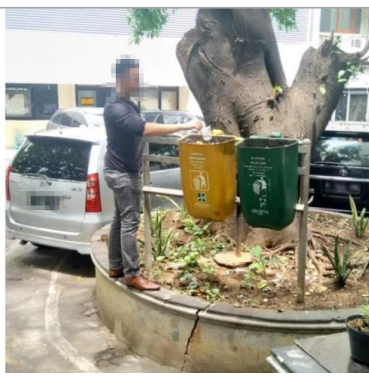

B 
that the trash bins were often incorrectly placed and even inaccessible (see Figs. 10 and 11). Another problematic example, shown in Fig. 11, features trash bins near the entrance of SIL UI. The bins were relatively easy to see. However, they were elevated, making them difficult to reach. The reason for such a design choice is not known. It would require a calculated effort for a person of average height to properly dispose of trash in these bins, and we can assume that those who are shorter than average would find it even more difficult. As seen in Fig. 10, trash bins are placed behind a parking slot post, making them practically invisible. Even when someone can see them, the bins are still difficult to access.

Further observations showed that visual indicators for the bins were relatively normative in the form of strict prohibitive signs only, nothing too provoking that forces people to stop littering. It is amusing to see a prohibitive sign that forbids smoking printed in large-scale letters and campus residents openly smoking nearby (see Fig. 12). Therefore, it is probably not the size of the prohibitive sign that matters, but how the sign's message is expressed ensures that people will take heed of it.

Fig. 12. (A) Large-scale banner; (B) smokers still persist

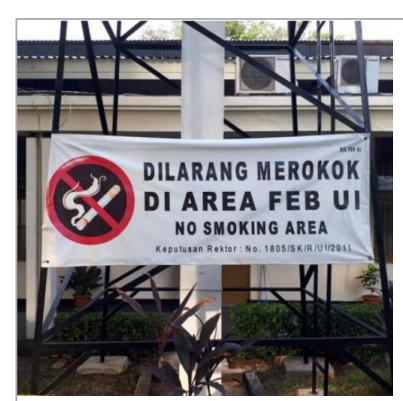

A

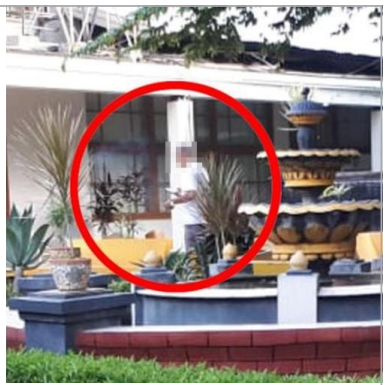

B
Trash bins meant for two different disposal methods (organic waste and non-organic waste) are often near each other for waste management purposes (Fig. 13). The problem is that both trash bins usually end up with both waste items. Why does this continue to happen, even with clearly labeled signs? Are people simply too lazy to correctly dispose of their trash? Both waste bins have different colors with different labels. The organic bin is green, and the non-organic bin is blue. However, it is unclear whether people know the meaning behind the colors and labels. It is also possible that they do not know how to differentiate between organic and non-organic items. Furthermore, the shade of blue chosen for the non-organic bin is a blue-gray, which is considered to be an invisible color. In Fig. 13, the non-organic bin is almost concealed by the row of blue chairs nearby. As the bins are somewhat separated, it is also possible that people choose them based on convenience, using the closer bin rather than walking to the correct one.

Fig. 13. Organic and non-organic trash bins

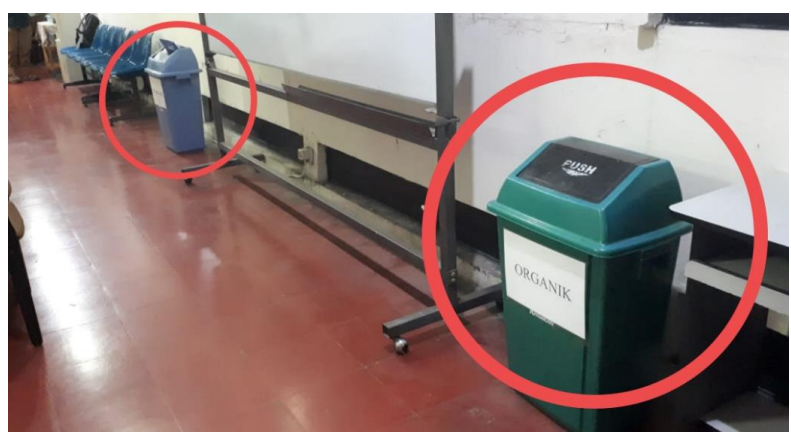

From the researchers' observations, it is seen that the design of waste management signs and posters is quite uninformative. The placement of trash bins was also incorrect and prevented people from disposing of their waste properly. Hence, the researchers attempted to design new signs and posters based on literature studies regarding visually pleasing images. The following four were constructed:

1 Prohibitive signs based on theories regarding images that are considered to be visually pleasing;

2 Trash bin labels with more informative labels;

3 Trash bin designs that are more compact, accessible, and informative;

4 Encouragement posters that were encouraging rather than prohibitive.

We also wanted to know how the public would react to these compared with the conventional waste management signs. 
The authors created two types of design: one based on proper rules and theories of design and one that was not. These designs were reviewed by respondents to determine their reactions and preferences. Because the majority of the respondents were native Indonesian, the signs were made using the Indonesian language. We decided to create both favorable and unfavorable designs for use in the study.

The prohibitive signs are shown in Fig. 14. Fig. 14A is a favorable sign based on the Golden Ratio, with balanced proportions, good color contrast, minimal wasted space, and a visual hierarchy based on the textual message. It uses the Impact font because of its strong feeling of authority. Fig. 14B's design had unbalanced proportions, wasted space, slightly misaligned word placement, imbalanced colors, and an unbalanced visual hierarchy. The Arial font gives it a

Fig. 14. Organic and non-organic trash bins

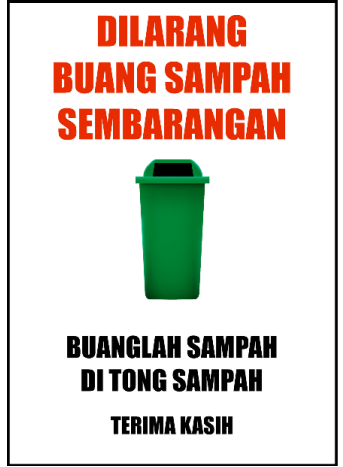

A

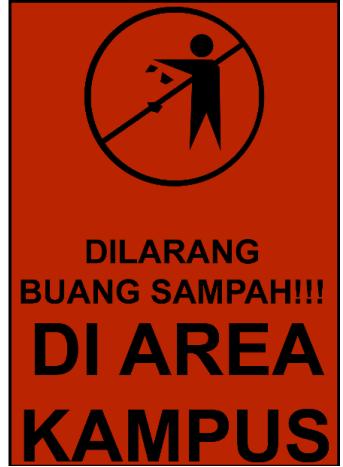

B

Fig. 15. Proportion of each design in relation to the Golden Ratio

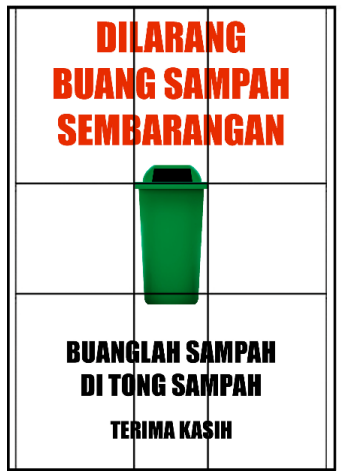

A

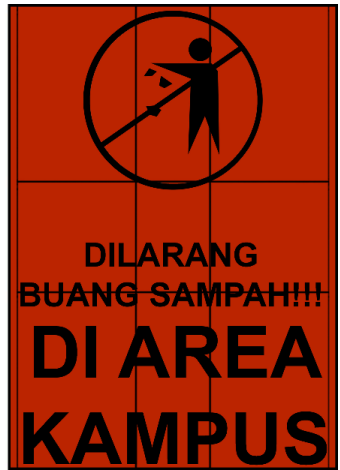

B casual feel with authority. Both designs were drawn digitally, and to avoid copyright, no existing images were used.

Next, for uninformative bin labels, the authors designed more user-friendly labels. The bins were distinguished from each other by two different bright colors and labeled with simple definitions of organic and non-organic, as well as with examples of the kind of waste that each bin is intended to hold. The design is given in Fig. 16.

The researchers also designed normative versions of the labels (Fig. 17) to compare the public opinion. These bin designs were made utilizing multiple stock photos that were free of copyright license (provided by

Fig. 16. Organic and non-organic trash bins with appropriate labels

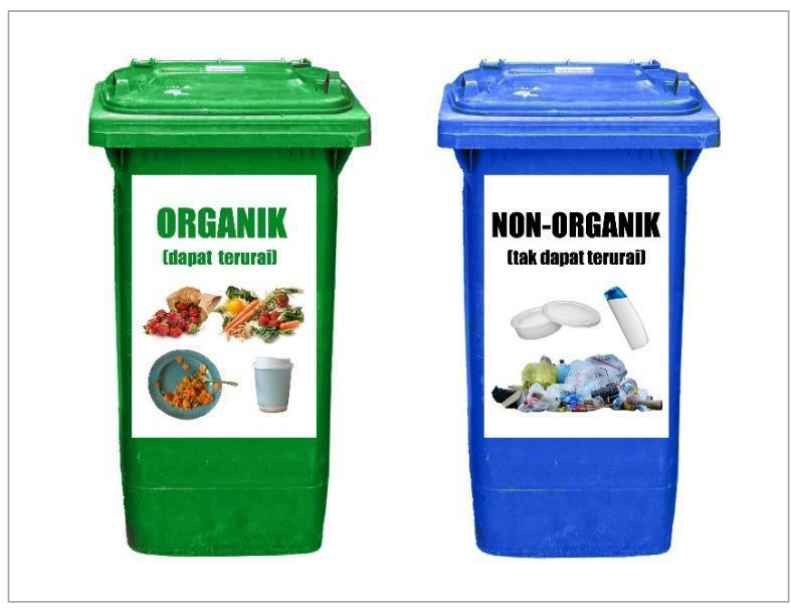

Fig. 17. Organic and non-organic trash bins with conventional labels

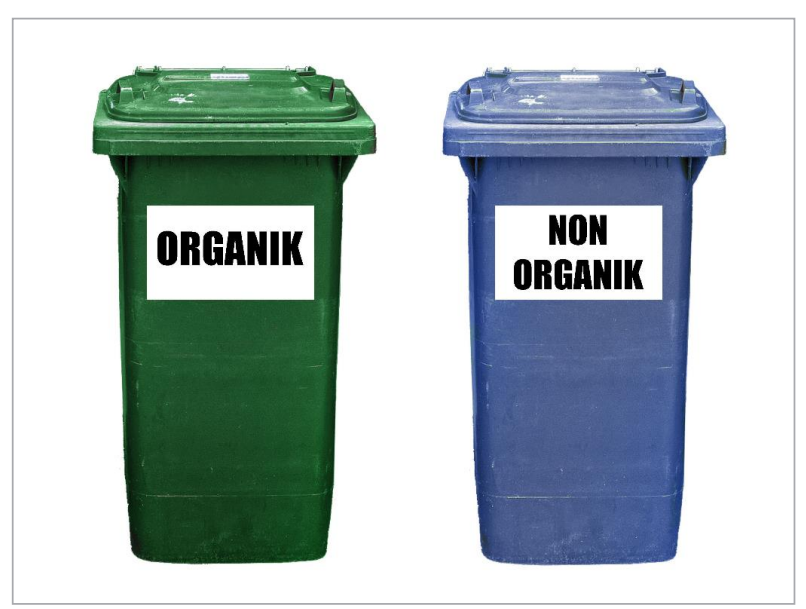


Pixabay). The individual stock photos gathered were then edited purposively using Adobe Photoshop.

To correct the potential errors with the separation of trash into different bins, the researchers designed a double-decker trash bin (Fig. 18), where the upper half holds organic waste and the bottom half holds non-organic waste. The researchers also obtained feedback from the respondents on the design, which was created using a 3D modeling software called SketchUp.

Fig. 18. Double-decker trash bin

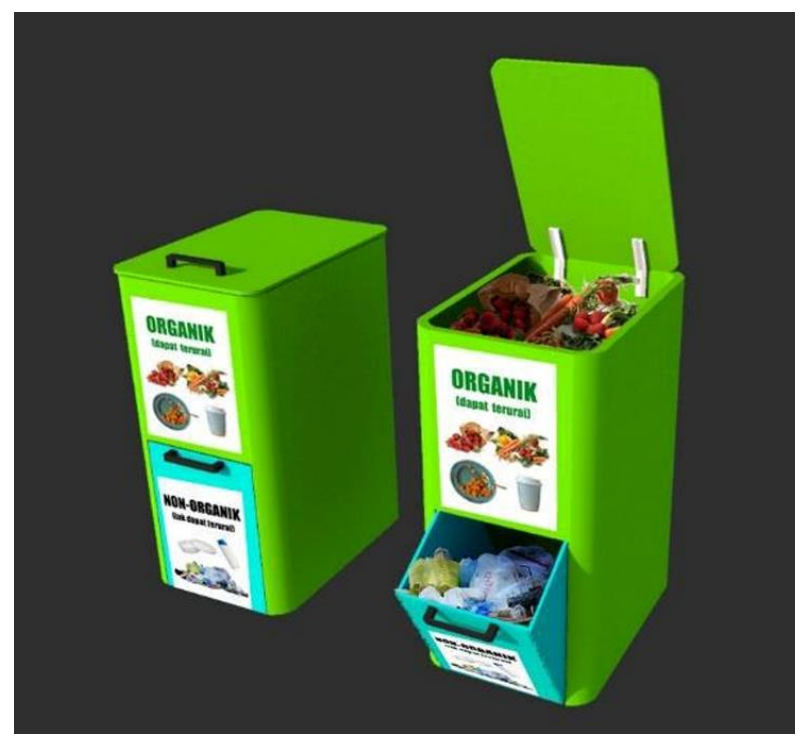

Finally, we tried to determine which visual aids were preferred by the public: prohibitive signs or encouragement posters. For this purpose, we evaluated images on Pixabay that we believed could capture the idea we had in mind and that fitted with the rules and theories of visual design. We adopted the same technique used by the cigarette corporations in marketing their products and made the images seem "elegant" and "cool." The original image is given in Fig. 19.

We edited for our purposes using Adobe Photoshop CS3 software. We wanted to (i) encourage the audience with an image of clean living depicted by disposing of waste in a trash bin using an elegant gesture and (ii) link it with the lifestyle of a lady or gentleman. The edited image is given in Fig. 20.
Fig. 19. Original image provided by Pixabay

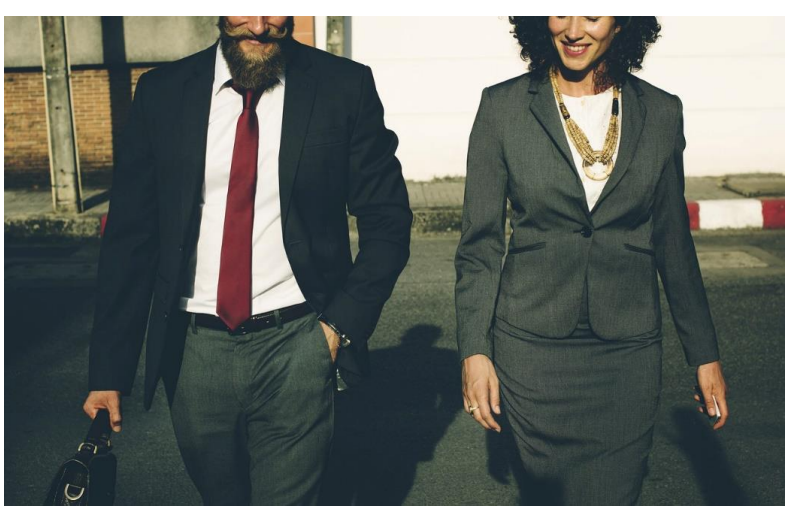

Fig. 20. Edited image meant for encouragement

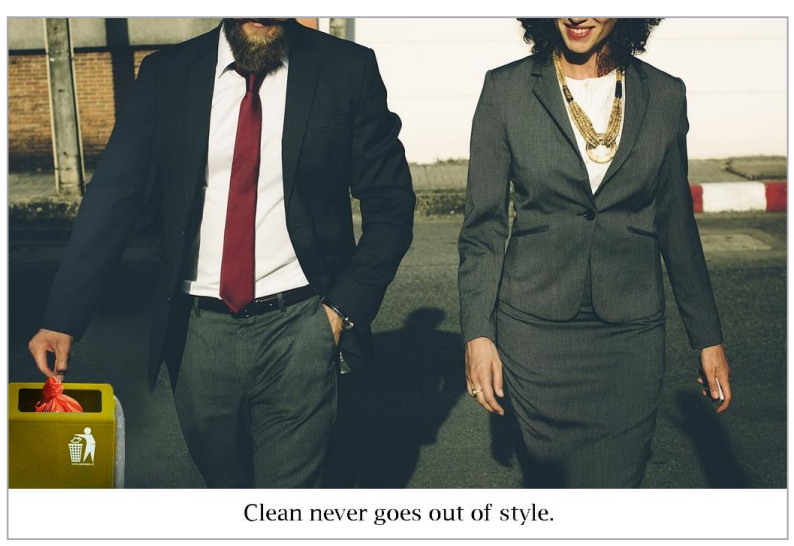

We altered the image slightly: the man in the business suit holding a briefcase was changed to him placing a plastic bag in a yellow recycling bin. The color scheme of orange and yellow was meant to draw the audience's attention toward the message of the image. We also added a short quote below the image, similar to those found on motivational posters, to emphasize that cleanliness is linked with class and elegance. The font used was Lucinda Bright, which is generally associated with professional purposes. The message "Clean never goes out of style" was written in English to further give it a professional feel. The message was formulated to indicate that what makes someone classy is not the clothes they wear, but their manners. The designs were formulated to elicit community responses regarding the alternatives suggested in the study. Additionally, we created a questionnaire directed toward the residents of SIL UI (students, teachers, 
and staff) regarding their activities on the campus. The results showed that of 33 respondents, 100\% agreed that they were bothered by the presence of litter on campus and that they felt it lowered the aesthetics of their campus, with $90.9 \%$ of them affirming that they often see litter in gutters and drains. This information is gained based on a yes or no question "I often see plastic waste in gutters and drains in nearby areas." Exactly $97 \%$ of the respondents were fully aware that littering can cause problems such as the buildup of waste in rivers resulting in floods, based on the yes or no question "I acknowledge that one of the reasons of flood in Jakarta is plastic waste build up in rivers." A full 100\% of the respondents were aware it could pollute the sea and its biotas, based on the yes or no question "I acknowledge that plastic waste that are washed from rivers to the sea can destroy sea life and terminate sea biotas." Besides, $100 \%$ were aware that it could seriously affect the environment, based on the yes or no question "I realize that littering can have a serious implication to the environment."

For the next question, we asked the respondents to agree or disagree with the statement "I have personally witnessed my colleagues/friends littering." Surprisingly, $84.8 \%$ confessed to witnessing their peers littering, and $81.8 \%$ approached them to address the issue. Thus, it can be said that the residents of SIL $\mathrm{UI}$ litter quite frequently, and their peers generally address the issue. Although the responses indicated a large amount of litter, they also indicated a large amount of concern evidenced by people addressing the issue.

About $81.8 \%$ of the respondents confirmed that they often saw prohibitive signs and trash bins on campus, indicating that these are easily seen. However, only $63.6 \%$ of the respondents stated that they could easily access the bins, and this was in line with our previous observations about bin accessibility. Only $72.7 \%$ of the respondents felt they understood the meaning behind the trash bin colors. This means that the utilization of color separation for trash management might not be fully effective. Since $97 \%$ of the respondents stated that they understood the meaning of the terms organic and non-organic, people may prefer the use of labels to color divisions. Slightly over half (51.5\%) of the respondents agreed that often the signs and trash bin types were more confusing than helpful. A majority of the respondents $(66.7 \%)$ perceived the signs that were balanced in proportion, color, and visual hierarchy as easier to see and that the message was easier to grasp. Moreover, $97 \%$ preferred trash bins with bright colors and labels that displayed examples of where to dispose of specific items (see Fig. 21).

Fig. 21. Preferable signs and labels

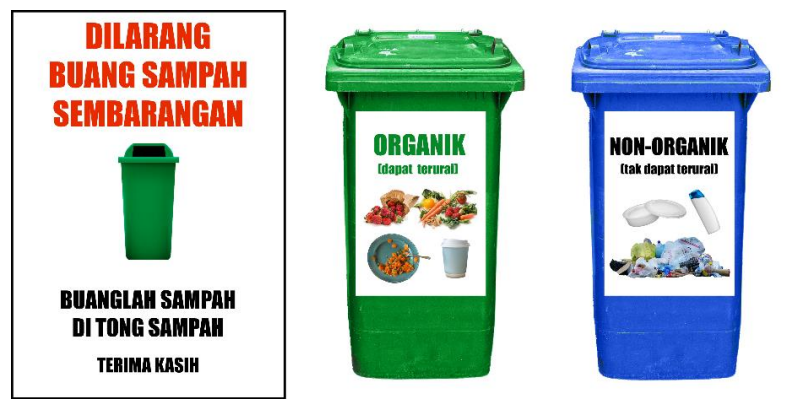

We tried to design a more accessible and less time-consuming single trash bin with separate compartments for organic and non-organic trash. However, only $45.5 \%$ of the respondents agreed that this design was more effective and $54.5 \%$ preferred the conventional design. This may mean that there are more variables and reasons for people's failure to correctly dispose of their trash.

About $66.7 \%$ of the respondents stated that they preferred the encouragement posters to the prohibitive signs. The response is identical to the previous question regarding which prohibitive signs are more favorable. We could assume that the same respondents who chose the more visually pleasing signs also agreed that encouragement was better than normative prohibition. This may point to the possibility that the use of encouragement in the form of appropriate and visually pleasing images can be utilized to increase awareness and thus prevent littering. The results of the study show that signs and symbols of environmentally friendly behavior in the form of waste disposal should be placed proportionally. The results are similar to Lukito et al.'s (2021) study in the use of signage in zoos that proportionally increases visitor satisfaction. 


\section{Conclusions}

SIL UI in 2019 was generally free of litter, although instruments such as signs and trash bins were often ill-placed and inaccessible for public use. Better designs in the form of more visually balanced prohibitive signs, more informative trash bin labels, and visually pleasing encouragement posters may bring about improvements in littering behaviors. The results showed that the respondents perceived the new designs positively, except for the double-decker trash bin design.

\section{References}

Almosa, Y., Parkinson, J., and Rundle-Thiele S. (2017) Littering reduction: a systematic review of research 19952015. Social Marketing Quarterly 23(3): 203-222. https://doi. org/10.1177/1524500417697654

Barley, T. N. (2011) The bitter truth: littering is a Jakarta epidemic. Available at: https://jakartaglobe.id/archive/the-bitter-truth-littering-is-a-jakarta-epidemic/ (accessed 7 December 2018).

Bateson, M., Nettle, D. and Roberts, G. (2006) Cues of being watched enhance cooperation in a real-world setting. Biology Letters 2: 412-414. https://doi.org/10.1098/rsbl.2006.0509

Bateson, M., Callow, L., Holmes, J. R., Redmond Roche, M. L., and Nettle, D. (2013) Do images of 'watching eyes' induce behaviour that is more pro-social or more normative? A field experiment on littering. PLOS ONE 8(12): 0082055. https://doi. org/10.1371/journal.pone.0082055

Batista, C. R. and Filho, A. M. do V. (2019) The golden ratio and jewelry design. Advances in Intelligent Systems and Computing 809: 2159-2162. https://doi.org/10.1007/978-3-319-95588-9_192

BBC News. (2018) Dead sperm whale found in Indonesia had ingested '6kg of plastic'. Available at: https://www.bbc.co.uk/ news/world-asia-46275742 (accessed 7 December 2018).

Bo, Y., Yu, J. and Zhang, K. (2018) Computational aesthetics and applications. Visual Computing for Industry, Biomedicine, and Art. 1. https://doi.org/10.1186/s42492-018-0006-1

Brechwald, W. A., Prinstein, M. J. (2011) Beyond homophily: A decade of advances in understanding peer influence processes. Journal of Research on Adolescence 21(1): 166- 179. https:// doi.org/10.1111/j.1532-7795.2010.00721.x

Brown, B. B., Bakken, J. P., Ameringer, S. W. and Mahon, S. D. (2008) A comprehensive conceptualization of the peer influence

\section{Acknowledgement}

This research was carried out under the supervision of the School of Environmental Science of Universitas Indonesia, specifically under the research cluster Interaction, Community Engagement and Social Environment (social.sil.ui.ac.id). The authors thank the Research and Innovation Management Product Office (KPPRI) of Universitas Indonesia and ENAGO for the English language review.

process in adolescence. In M. J. Prinstein and K. A. Dodge (Eds.), Understanding peer influence in children and adolescents (pp. 17-44). New York: The Guilford Press.

Brown, T. J., Ham, S. H. and Hughes, M. (2010) Picking up litter: An application of theory-based communication to influence tourist behaviour in protected areas. Journal of Sustainable Tourism 18(7): 879-900. https://doi.org/10.1080/09669581003721281

Burnham, T. C., Hare, B. (2007) Engineering human cooperation - Does involuntary neural activation increase public goods contributions? Humans Nature 18: 88-108. https://doi. org/10.1007/s12110-007-9012-2

Cerrato, Herman. (2012) The meaning of colors. Available at: http://www.hermancerrato.com/graphic-design/images/ color-images/the-meaning-of-colors-book.pdf (accessed 27 September 2019).

Eldesouky, D. F. B. (2013) Visual hierarchy and mind motion in advertising design. Journal of Arts and Humanities 2(2): 148162.

Long, J., Harré, N. and Atkinson, Q. D. (2015) Understanding Change in Recycling and Littering Behavior Across a School Social Network. American Journal of Community Psychology 53(3-4): 462-474. https://doi.org/10.1007/s10464-015-9706-2

Lukito, Y. N., Kusuma, N. R., Arvanda, E, and Ummah, Z. R. (2021). Designing with Users: A Participatory Design as a Community Engagement Program in the City Zoo. ASEAN Journal of Community Engagement 5(1): 49-70. https://doi.org/10.7454/ ajce.v5i1.1079

Mxreb0. (2006) Club 33, Disney Land.

Nettle, D., Harper, Z., Kidson, A., Stone, R., Penton-Voak, I. S. and Bateson, M. (2012a). The watching eyes effect in the Dictator Game: It's not how much you give, it's being seen to give 
something. Evolution and Human Behavior 34: 35-40. https:// doi.org/10.1016/j.evolhumbehav.2012.08.004

Nettle, D., Nott, K. and Bateson, M. (2012b) 'Cycle thieves, we are watching you': impact of a simple signage intervention against bicycle theft. PLOS ONE 7. https://doi.org/10.1371/ journal.pone.0051738

EPI (Earth Policy Institute). (2014) Plastic bags fact sheet. Available at: http://www.earth-policy.org/mobile/releases/plastic_bags_fact_sheet (accessed 1 December 2018).

Ernest-Jones, M., Nettle, D. and Bateson, M. (2011) Effects of eye images on everyday cooperative behavior: a field experiment. Evolution and Human Behavior 32: 172-178. https://doi. org/10.1016/j.evolhumbehav.2010.10.006

Francey, D., Bergmüller, R. (2012) Images of eyes enhance investments in a real-life public good. PLOS ONE 7: e37397. https://doi.org/10.1371/journal.pone.0037397

Geyer, R., Jambeck, J. R. and Law, K. L. (2017) Production, use, and fate of all plastics ever made. Science Advances 3(7): e1700782. https://doi.org/10.1126/sciadv.1700782

Healey, M. (2015) Engaging students as partners and as change agents. UK: University of Gloucestershire.

Holland, A., Simpson, A. and Riggs, K. J. (2015) Young children retain fast mapped object labels better than shape, color, and texture words. Journal of Experimental Child Psychology 134: 1-11. https://doi.org/10.1016/j.jecp.2015.01.014

Jambeck, J. R., Geyer, R., Wilcox, C., Siegler, T. R., Perryman, M., Andrady, A., Narayan, R. and Law, K. L. (2015) Plastic waste inputs from land into the ocean. Marine Pollution 347(6223): 768-771. https://doi.org/10.1126/science.1260352

Keep Calm and Posters. (2015) Keep calm and jaga kebersihan poster. Available at: http://www.keepcalmandposters.com/ poster/3668176_keep_calm_and_jaga_kebersihan (accessed 7 December 2018).

Keller, J., Pfattheicher, S. (2011). Vigilant self-regulation, cues of being watched and cooperativeness. European Journal of Personality 25: 363-372. https://doi.org/10.1002/per.797

Liu, Q. (2018) Graphic creative design based on subconsciousness theory. NeuroQuantology 16(6): 471-477. https://doi. org/10.14704/nq.2018.16.6.1646

Ocean Conservancy and McKinsey Center. (2017) Stemming the tide: land-based strategies for a plastic - free ocean. McKinsey and Company.

Oda, R., Niwa, Y., Honma, A. and Hiraishi, K. (2011) An eyelike painting enhances the expectation of a good reputation. Evolution and Human Behavior 32: 166-171. https://doi. org/10.1016/j.evolhumbehav.2010.11.002
Ojedokun, 0. (2011) Attitude towards littering as a mediator of the relationship between personality attributes and responsible environmental behavior. Waste Management 31: 2601-2611. https://doi.org/10.1016/j.wasman.2011.08.014

Ojedokun, A. O., Balogun, S. K. (2010) Environmental attitude as a mediator of the relationship between self-concept, environmental self-efficacy and responsible environmental behavior among residents of high density areas in Ibadan metropolis, $\mathrm{Ni}$ geria. Ethiopian Journal of Environmental Studies and Management 3(2): 111-119. https://doi.org/10.4314/ejesm.v3i2.59834

Ojedokun, A. O., Balogun, S. K. (2011) Psycho-sociocultural analysis of attitude towards littering in a Nigerian Urban City. Ethiopian Journal of Environmental Studies and Management 4(1): 68-80. https://doi.org/10.4314/ejesm.v4i1.9

Police Executive Research Forum. (2016) Guiding principles on use of force. United States of America: Police Executive Research Forum.

Powell, K. L., Roberts, G. and Nettle, D. (2012) Eye images increase charitable donations: evidence from an opportunistic field experiment in a supermarket. Ethology 118: 1096- 1101. https://doi.org/10.1111/eth.12011

Share Faith. (2013) Learn the basic tools of visual hierarchy. Available at: https://www.sharefaith.com/blog/2013/09/learn-basic-tools-visual-hierarchy/ (accessed 7 December 2018).

Tapp, A., Rundle-Thiele, S. (2016) Social marketing and multidisciplinary behaviour change. In F. Spotswood (Ed.), Beyond Behaviour Change: Key Issues, Interdisciplinary Approaches and Future Directions (pp. 135-156). Bristol: Bristol University Press. https://doi.org/10.1332/policypress/9781447317555.003.0007

Talltanic. (2018) HIDDEN disneyland secrets. Available at: https://www.youtube.com/watch?v=ROCYOQO qDu4an$\mathrm{dt}=236 \mathrm{~s}$ (accessed 7 December 2018).

Taylor, A., Curnow, R., Fletcher, T. and Lewis, J. (2007) Education campaigns to reduce stormwater pollution in commercial areas: do they work? Journal of Environmental Management 84(3): 323-335. https://doi.org/10.1016/j.jenvman.2006.06.002

The Beat. (2017) Back to basics: the rule of thirds in filmmaking. Available at: https://www.premiumbeat.com/blog/rule-ofthirds-filmmaking/ (accessed 7 December 2018).

Thrive Advertising. (2012) Color me happy. Available at: https:// thriveadvertising.wordpress.com/2012/04/30/color-me-happy/ (accessed 7 December 2018).

Thomas, B. (2018) Beautiful contrast colors photos of coloring pages picture. Available at: https://colossal-squid.com/tag/ good-contrast-colors-for-yellow/ (accessed 7 December 2018). UNEP (United Nations Environment Programme). (2018) Single use plastics: a roadmap for sustainability. UNEP. 
WEF (World Economic Forum). (2016) The new plastics economy: rethinking the future of plastics. Geneva: WEF.

White, K. M., Hyde, M. K. (2011) The role of self-perceptions in the prediction of household recycling behavior in Australia. Environment and Behavior 44(6): 785-799. https://doi. org/10.1177/0013916511408069
World Medical Association. (2013) WMA Declaration of Helsinki - Ethical Principles for Medical Research Involving Human Subjects. Available at: from https://www.wma.net/policies-post/ wma-declaration-of-helsinki-ethical-principles-for-medical-research-involving-human-subjects/ (accessed 27 September 2019). 